\title{
BAMBU LAMINADO COLADO TERMO-TRATADO: DIMENSÕES ESTRATÉGICAS NA PRODUÇÃO DE MÓVEIS SUSTENTÁVEIS
}

\author{
Rodrigo Rocha Carneiro \\ UNESP - Bauru \\ contato.rodrigorochadesign@gmail.com \\ Prof. Dr. Marco Antônio dos Reis Pereira \\ UNESP - Bauru \\ pereira@feb.unesp.br
}

Resumo: Com a crescente escassez de recursos naturais e a demanda por soluções sustentáveis na fabricação de produtos, o bambu revela-se como alternativa eficaz para produção de artefatos nos mais variados segmentos. Sua versatilidade, propriedades físico-mecânicas e estética já foram comprovadas sendo possível encontrar no mundo todo excelentes exemplos de sua aplicação. Infelizmente, no Brasil esse material é pouco explorado e referências sobre métodos de beneficiamento do bambu laminado colado (BLaC) são muito raras quando nos referimos a obtenção de resultados estéticos com o material. $O$ desenvolvimento de técnicas aplicáveis ao design torna-se fundamental para revelar o bambu como madeira alternativa viável para produção de móveis e atrativa para o mercado consumidor. O presente artigo visa desenvolver uma revisão bibliográfica para fundamentar a viabilidade do desenvolvimento de metodologias para obtenção de novas tonalidades de BLaC por meio de técnicas de tratamento térmico aplicáveis ao design de mobiliário, com o objetivo de ampliar a versatilidade dessa matéria-prima para o mercado moveleiro.

Palavras-chave: design de mobiliário, bambu laminado colado termotratado, sustentabilidade

\begin{abstract}
With the increasing scarcity of natural resources and the demand for sustainable solutions in the manufacture of products, bamboo is revealed as an effective alternative to producing artifacts in various sectors. Its versatility, physical and mechanical properties and aesthetics have proven it is possible to find in the world all excellent examples of its application. Unfortunately, in Brazil this material is underexplored and references on the glued laminated bamboo processing methods (BLaC) are very rare when we refer to obtain aesthetic results with the material. The development of techniques applicable to the design is fundamental to reveal the bamboo wood as a viable alternative for the production of
\end{abstract}


furniture and attractive to the consumer market. This article aims to develop a literature review to support the feasibility of developing methodologies for obtaining new shades BLAC by heat treatment techniques applicable to furniture design, with the aim of expanding the versatility of this raw material to the market furniture.

Keywords: furniture design, glued laminated bamboo heat-treated, sustainability

\section{INTRODUÇÃO}

A prática do Design, desde sua ascensão na Revolução Industrial, permitiu o surgimento de artefatos cada vez mais diferenciados e contribuiu, em paralelo a outros fatores, com a ascensão do consumo. A inovação como prática competitiva entre fabricantes diminuiu o ciclo de vida dos produtos e a tecnologia permitiu a redução dos custos de produção, o que ampliou a demanda por novidades acrescentando à essa dinâmica um processo de consumo e descarte mais numeroso e acelerado.

A pressão desse processo sobre os recursos naturais despertou em todos os personagens desse ciclo uma reflexão sobre as consequências a médio e longo prazo dessas práticas. O designer, sendo um potencializador desse processo, tem como responsabilidade ser consciente dos impactos de suas ações projetuais, viabilizando o resultado de seu trabalho para atender às necessidades da indústria ao mesmo tempo que se reduz os danos ao meio ambiente e à sociedade ou seja, agir de forma sustentável.

Dentre os caminhos possíveis temos o bambu. Conhecido como a madeira do futuro, possui ótimas características físico-mecânicas, facilidade de produção e manejo, sendo uma grande alternativa aos problemas florestais. Dentre os seus derivados, o bambu laminado colado (BLaC) é sem dúvida a sua forma mais promissora, podendo ser aplicado à produção de móveis. Nota-se porém, que no Brasil essa cultura ainda é pouco explorada, havendo apenas a sua presença em pequenos utensílios domésticos de baixo custo, em geral importados da China. Torna-se necessário portanto, considerar aplicações e técnicas de beneficiamento que coloquem o bambu em um patamar de matéria-prima de valor agregado, capaz de substituir a madeira não apenas nos processos fabris, mas também nas necessidades de mercado.

Uma técnica muito difundida na indústria madeireira, no tocante a melhoria da resistência da madeira, é o tratamento térmico, ou termorretificação. Essa técnica, não apenas protege a madeira como também altera a sua coloração, pois submete 0 material a elevadas temperaturas em um processo de pré-carbonização. Sua utilização no BLaC já é presente na China, principalmente na confecção de pisos, elevando a versatilidade do material ao oferecer no mercado produtos com diferentes opções de cores ainda ao aspecto natural, sem utilização de corantes ou vernizes. Porém não encontramos referências que apontam a viabilidade dessa técnica para a confecção de móveis.

Com o intuito de contribuir para os estudos acerca do bambu e suas diversas aplicações no design de mobiliário, o presente projeto pretende desenvolver a partir de uma revisão bibliográfica, fundamentos que justifiquem a viabilidade de 
construções de metodologias de aplicação do BLaC termotratado no design de mobiliário, colaborando com sua atratividade comercial ao permitir que o mesmo possa ser visto como matéria-prima competitiva ao ser apresentado em diversas opções estéticas para o mercado.

\section{DESENVOLVIMENTO}

\subsection{O uso da madeira e suas consequências}

O aumento da produção industrial a partir da II Guerra Mundial alterou mais e em menor tempo a cultura de consumo de produtos e serviços, no entanto, percebese que os padrões adotados atualmente nos levam a reconhecer a inviabilidade da exploração indiscriminada de recursos naturais (GUIMARÃES, 2009). 80\% desse aumento se deu entre 1950 e 1997 quando a degradação do meio ambiente aumentou em grande escala e a cobertura total de florestas tropicais reduziu em 25\% (FUADLUKE, 2010).

A emissão de $\mathrm{CO} 2$ é outro grande problema, sua contribuição para o efeito estufa ultrapassa os $50 \%$. Manzini e Vezolli $(2008$, p. 328) afirmam que de todo o CO2 produzido " $80 \%$ provém dos processos de transformação energética (em particular petróleo e carvão), $17 \%$ através das produções industriais e os restantes $3 \%$ através dos desmatamentos florestais". O processamento da madeira está presente nas três cadeias citadas e se considerarmos que parte dos desmatamentos são provenientes de incêndios, esses números ficam ainda mais alarmantes.

Em paralelo, temos a realidade dos produtos resultantes do processamento da madeira, em especial o mobiliário. Antes da Revolução Industrial os móveis eram feitos sob encomenda com a participação ativa do cliente e do marceneiro na escolha dos tipos de madeira e no acompanhamento das etapas de produção. O móvel era um bem durável, tornando-se herança e um reflexo de expressão cultural. Com a industrialização e a substituição do marceneiro pelo designer, o móvel passa a ser um produto acabado que levamos no ato da compra (KAZAZIAN, 2009). Essa dinâmica de consumo tirou o valor patrimonial do objeto que, na contemporaneidade, passou a ter como principal designação refletir a personalidade de seu proprietário. Hoje, o móvel é facilmente descartado e substituído por uma nova moda criada por ações de marketing.

Essa commoditização, não considerou o ciclo de vida desses produtos que causam impacto não apenas na fase de produção. As tintas e vernizes, muitas vezes utilizados não apenas para tratamento da madeira mas por demandas estéticas são extremamente nocivos ao homem e à natureza. Kazazian (2009, p. 122 e 123) relata que "... alguns móveis fabricados a partir da madeira tratada provocam emissões tóxicas nas habitações em forma de gases, responsáveis, entre outras coisas, por enxaquecas e alergias respiratórias". O mesmo autor relata ainda que, no ato do descarte, essas substâncias são levadas pela chuva, contaminando solos e lençóis freáticos.

\subsection{O valor estético da mercadoria}

Em um panorama industrial globalizado onde o número de concorrentes e de produtos ofertados aumentam, ao mesmo tempo em que o consumidor possui opções de compra variadas, a necessidade de diferenciação e posicionamento tornam-se fundamentais para a sobrevivência das empresas. O marketing, há muito, identificou o 
design, como ferramenta fundamental nesse ambiente em crescente padronização. Para Kotler e Keller (2006, p. 371) o design tem um papel importante no mercado, pois o mesmo "é o fator que oferecerá uma constante vantagem competitiva". Infelizmente a função inovadora do design vem sendo substituída por práticas cosméticas cada vez mais elaboradas e copiadas. Postrel (2004 apud KOTLER; KELLER, 2006) relata que em um mercado muito competitivo a estética passa a ser, geralmente, a única forma de destacar um produto.

Segundo Lipovetsky (1989, p.160) “A lei é inexorável: uma firma que não cria regularmente novos modelos perde em força de penetração no mercado e enfraquece sua marca de qualidade numa sociedade em que a opinião espontânea dos consumidores é a de que, por natureza, o novo é superior ao antigo." Essa dinâmica criada pela moda e reforçada por ferramentas de marketing colocou a aparência estética num patamar de valor de uso prometido, onde sua existência se torna um meio motivador da compra, um instrumento para se obter dinheiro (HAUG, 1997).

É fato que a indústria moveleira é identificada como uma das mais conservadoras da atual estrutura produtiva (ROSA et al., 2007). Não significa que não haja progresso técnico no setor, mas sim que o mesmo não é imprescindível para a competição entre as empresas. As principais inovações geradas ao longo das décadas são oriundas dos fornecedores de matérias-primas. Sendo assim o reconhecimento da função estética do produto como ferramenta de venda tornou-se a principal saída para a sobrevivência dessas empresas.

Uma das formas encontradas pelo setor para garantir a variabilidade de portfólio e a adequação às chamadas tendências ditadas pela moda foi o emprego, ao longo de sua história, de tipos diferentes de madeira nativas (madeiras de lei). Essa postura permitia a oferta de móveis em cores variadas, além de diferentes características de resistência, durabilidade e usinabilidade. Com a crescente escassez desses recursos e com o avanço da tecnologia essas maneiras passaram a ser processadas em lâminas para revestir painéis de aglomerados, compensados e MDFs (ROSA et al., 2007). Essa prática diminui custos de produção e conserva a oferta estética porém, $90 \%$ das espécies que vivem na terra abrigam-se nas florestas tropicais (Kazazian, 2009). Estudos da WWF Brasil relatam que entre os anos de 1970 e 2000 houve uma perda de biodiversidade de cerca de 35\% no planeta, comparável apenas a eventos de extinção em massa causados por desastres naturais e jamais pelo ser humano, como agora.

\subsection{Aspectos críticos e estratégicos do design sustentável}

Certamente o aspecto mais visível do termo sustentabilidade é a dimensão ambiental e, no design, vimos surgir frentes que questionam a forma atual de utilização dos recursos e de concepção de produtos. Dentre elas está o ecodesign, que procura prever o resultado desejado em todos os seus aspectos, considerando a renovação dos processos produtivos, bem como dos hábitos comportamentais, a fim de se alcançar uma maior sustentabilidade ambiental (BARBERO; COZZO, 2009). Infelizmente o ecodesign vai de encontro com a atual ordem capitalista que utiliza 0 design em prol de estratégias de mercado que priorizam a competitividade.

É fato que, apesar das inúmeras produções no tocante ao design sustentável, nosso discurso ainda está distante da efetiva implementação pois, não se alinhou de forma profunda com os aspectos econômicos imediatistas das empresas, talvez por 
isso não conseguimos desempenhar um papel tão eficiente nesse contexto. Mas se considerarmos Kazazian (2009, p. 30) "A economia e a ecologia podem ser pensadas juntas. As raízes etimológicas da economia evocam uma gestão do patrimônio sem despesa inútil ou uma relação entre as partes, enquanto a ecologia designa o estudo das relações que se produzem no espaço vivo."

Os argumentos para a implantação de inovações em termos de ecodesign se tornam mais simples se utilizarmos o discurso da gestão onde, sob o aspecto econômico é possível se obter redução de insumos, multas e penalidades por poluição em excesso; e sob o aspecto estratégico é possível ter ganhos como melhoria de imagem institucional, renovação de portfólio de produtos, aumento de produtividade, acesso aos mercados externos e melhoria no relacionamento com os steakholders ( governos, ONGs, comunidade, colaboradores, etc.) (NETO et al. 2011)

Existem ainda outros indicadores tanto no âmbito normativo, quanto no aspecto estritamente competitivo que apontam a tendência inevitável da importância de ações sustentáveis dentro das empresas e que devem ser considerados, como: as Normas de Gestão Ambiental ISO 14000, o selo verde e iniciativas como a da Bolsa de Valores de São Paulo (Bovespa), que seguiu o que já havia ocorrido no mercado internacional, criando em 2005 um índice de ações que fosse um referencial para investimentos: o Índice de Sustentabildade (ISE), que reflete o retorno de uma carteira de empresas engajadas com o tema (NETO et al. 2011).

Como atender, portanto, as questões ambientais sem entrar em conflito com os interesses empresariais, de forma que a sociedade possa também se beneficiar dos ganhos, mesmo nessa lógica onde o consumo é a máxima? E ainda: Como implementar soluções passíveis de serem aderidas no setor moveleiro, que possui uma tradição conservadora em termos de inovação tecnológica e é composto em sua maioria de pequenas e médias empresas? Como realizar essa transformação de forma imediata, diante da já presente escassez de recursos naturais?

\subsection{O bambu laminado colado}

Uma das saídas a essa problemática é a utilização de materiais renováveis de baixo impacto ambiental e, dentre as possibilidades que dialogam com a indústria moveleira, temos o bambu. "Por se tratar de uma planta tropical, perene, renovável e que produz colmos anualmente sem a necessidade de replantio, o bambu apresenta um grande potencial agrícola" (PEREIRA; BERALDO, 2008, p. 39). Além de ser um excelente sequestrador de carbono, possui ótimas características físicas, químicas e mecânicas podendo ser utilizado eficientemente em reflorestamentos, recuperação de matas ciliares, e regeneração ambiental. Em sua forma laminada e colada (BLaC) o bambu revela o seu aspecto mais promissor, pois possibilita uma ampla variedade de designs com estética única e aceitação no mercado internacional. Estudos desenvolvidos por Beraldo \& Abbade (2003, apud PEREIRA; BERALDO, 2008) evidenciaram que as características físicas e mecânicas do BLaC são plenamente favoráveis à utilização desse material na indústria de mobiliário. $\mathrm{O}$ bambu também é considerado uma das melhores madeiras para técnicas de curvatura. Ramos (2014) relata que "ao se aquecer o material a lignina entre as fibras torna-se mole, facilitando a curvatura em ângulos que só a madeira de Faia consegue igualar" (Figura 01). 

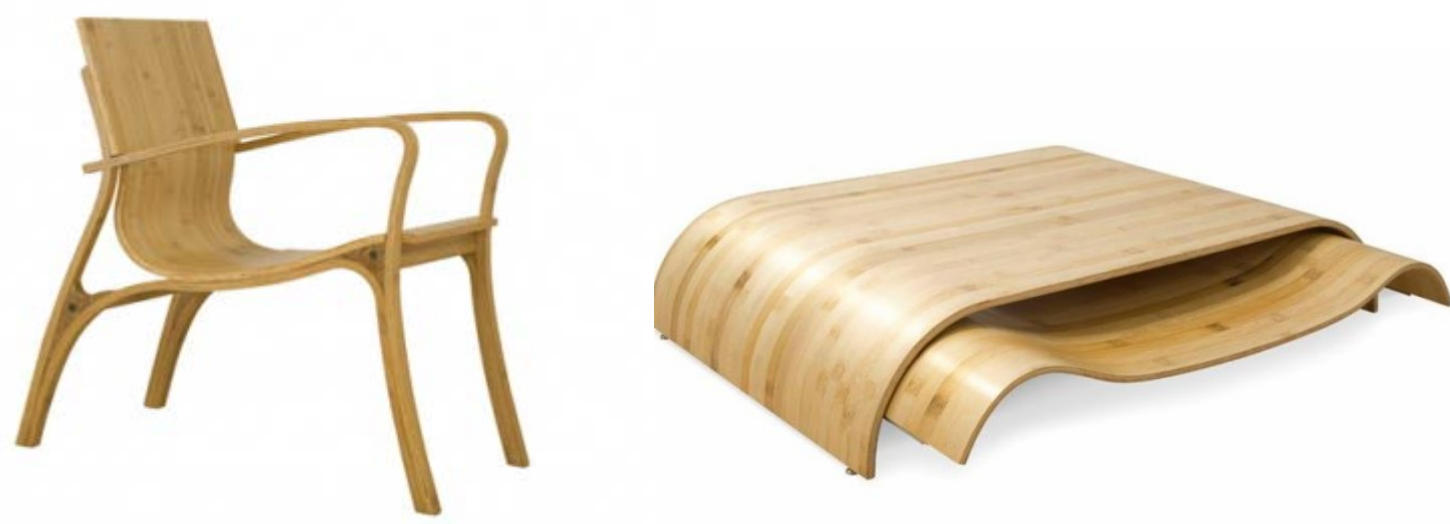

Figura 01 - Cadeira Bambu \#5 e Mesa Jabuti. Designer Paulo Foggiato

Fontes: Disponível em: http://www.novoambiente.com.br/v2/produto.php?id=1553 e em

http://delas.ig.com.br/colunistas/arteeinteriores/toda-a-versatilidade-do-bambu/c1237741394696.html

No Brasil foi sancionada uma lei que incentiva o bambu como matéria-prima importante na obtenção de serviços ambientais e promoção do desenvolvimento socioeconômico regional (Decreto-Lei 12484/11). Esse reconhecimento poderá facilitar a disseminação de seu uso na indústria como madeira alternativa. Todavia, uma das maiores barreiras para a aceitação do bambu no mercado talvez seja o seu uso popular em artesanatos e varas-de-pescar que lhe confere uma conotação negativa de rusticidade, baixo valor agregado e qualidade ruim, sob a ótica comercial.

Além disso, na dinâmica atual de mercado, onde a renovação de portfólio e a demanda por novidade é constante, é exigido que a versatilidade de uma matériaprima se estenda não apenas no aspecto funcional e de transformação formal, mas também no apelo estético. Este, por sua vez não pode ser concebido sem pensar nos impactos ambientais, visto que toda a cadeia produtiva deve ser sustentável para justificar a utilização de um material ecológico.

\subsection{0 tratamento térmico do bambu}

Um dos critérios fundamentais para o mercado, no tocante a estratégia de portfólio, é a profundidade de seu mix de produtos. Profundidade "refere-se a quantas opções são oferecidas em cada produto na linha" (KOTLER; KELLER, 2006, p. 375), característica importante quando se pretende alcançar um número maior de consumidores em um único item do portfólio. Um estudo pouco explorado sobre o BLaC, que pode servir como solução ao conceito de profundidade é o tratamento térmico, ou termorretificação. Segundo Brito et al. (2006 apud BRITO, 2013, p. 17), "a termorretificação é um processo que consiste na aplicação de calor na madeira em baixas temperaturas, com o intuito de promover a degradação de seus componentes químicos e fundamentais". Essa técnica é utilizada para garantir a durabilidade do material à pragas, como cupins. O resultado seria a obtenção de um produto sólido apresentando características diferenciadas, comparativamente à sua madeira original, algumas delas podendo tornar-se interessante para aplicações diferenciadas (BRITO et al., 2006). Moizés (2007) relata que na termorretificação do bambu é possível se obter de um mesmo material cores que vão do âmbar ao negro ao mesmo tempo que são modificados positivamente os aspectos relativos à durabilidade. Essa técnica, além de 
ser sustentável, elimina a necessidade de aplicação de produtos químicos para a obtenção de novos resultados estéticos (Figura 02).
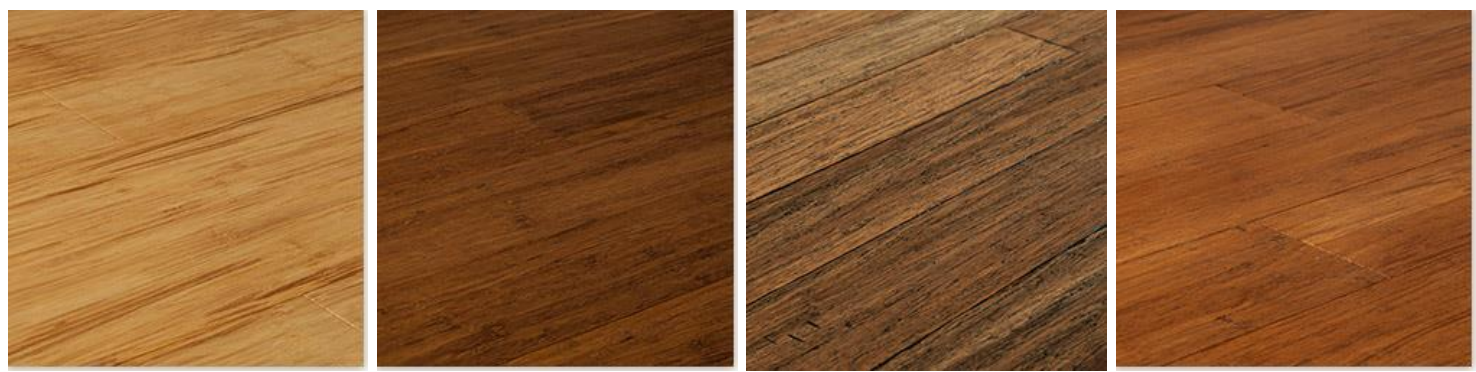

Figura 02: Pisos de bambu laminado colado termo-tratado, algumas tonalidades existentes Fonte: disponível em www.builddirect.com/Carbonized-BambooFlooring/Result_N_4294967291+4294966291+4294956590.aspx

A justificativa mercadológica é também ambiental, pois as madeiras de alto valor econômico - que são tropicais e já estão escassas - são apreciadas e reconhecidas no mercado mundial devido a cor e aos padrões de desenho. Sendo estes os principais atributos comerciais, a cor é um critério importante de qualidade, podendo inclusive definir o preço do produto final (Moura e Brito, 2011)

No Brasil, Brito (2013) e Colla (2010) realizaram testes tanto em taliscas, quanto em BLaC onde os mesmos foram submetidos à diversas temperaturas para posterior análise de suas propriedades. Estes estudos comprovaram a viabilidade do procedimento, porém não há referências sobre a sua aplicação no design de mobiliário, nem tão pouco uma metodologia que garanta o controle da obtenção da tonalidade desejada.

\section{CONCLUSÃO}

Ao considerarmos o contexto atual de escassez de recursos madeireiros, bem como os aspectos negativos de sua extração e consumo, conclui-se que que a indústria de mobiliário já vislumbra uma crise que se agravará, não apenas pelo apagão florestal, mas também pela pressão do mercado consumidor que, na contemporaneidade demanda por soluções cada vez mais personalizadas e criativas em termos de mobiliário, reflexo de uma prática mercadológica criada pela própria indústria. Em paralelo, conclui-se que a forma atual de produção e dinâmica de obsolescência de produtos é extremamente prejudicial ao planeta, visto que além dos impactos da extração de matérias-primas, há também os impactos ambientais do descarte dos produtos acabados.

Compreendeu-se também, que existem aspectos estéticos ligados ao mobiliário que não podem ser ignorados, pois são reflexos de uma cultura de consumo onde valores simbólicos do produto são levados em conta na movimentação da economia e que, portanto a inserção de soluções sustentáveis devem levar em consideração esse aspecto.

O bambu laminado colado é comprovadamente uma potencial alternativa na substituição da madeira e recentes pesquisas em tratamento térmico desse material, comprovaram que esse processo é seguramente aplicável, revelando o aspecto da versatilidade estética do mesmo, levantando portanto a hipótese de que o bambu 
pode atender a outros pré-requisitos comerciais na indústria moveleira. Sendo assim, torna-se necessário o desenvolvimento de metodologias que deem continuidade a essas pesquisas com foco no design de mobiliário, a fim de discutir sua aplicabilidade.

\section{REFERÊNCIAS}

BARBERO, Silvia; COZZO, Brunela. Ecodesign. Königswinter: H. F. Ullmann, 2009.

BRITO, Fláva Maria Silva. Efeito da termorretificação nas propriedades tecnológicas do bambu. 2013. 99f. Dissertação (Mestrado em Ciências Florestais) - Universidade Federal do Espírito Santo, Centro de Ciências Agrárias, Jerônimo Monterio, 2013.

COLLA, Wandivaldi Antonio. Efeito do tratamento térmico nas características físicas e mecânicas do bambu (DendrocalamusgiganteusMunro). 2010. 111f. Dissertação (Mestrado em Engenharia Agrícola) - Universidade Estadual de Campinas, Faculdade de Engenharia Agrícola, Campinas, 2010.

FUAD-LUKE, Alastair. Ecodesign: The Sourcebook, ThirdEditionFullyRevised. San Francisco: Chronicle Books LLC, 2010.

GUIMARÃES, Lia Buarque de Macedo. Design e Sustentabilidade: Brasil: produção e consumo, design sociotécnico. Porto Alegre: FEENG/UFRGS, 2009.

HAUG, Wolfgang Fritz. Crítica da estética da mercadoria. São Paulo: Fundação Editora da Unesp, 1997.

KAZAZIAN, Thierry. Haverá a idade das coisas leves. São Paulo: Editora Senac, 2009

KOTLER, Philip; KELLER, Kevin Lane. Administração de Marketing. São Paulo: Pearson Prentice Hall, 2006.

LIPOVETSKY, Gilles. 0 império do efêmero: a moda e seu destino nas sociedades modernas. São Paulo: Companhia das Letras, 1989.

MANZINI, Ezio; VEZZOLI, Carlo. O Desenvolvimento de Produtos Sustentáveis: os requisitos ambientais dos produtos industriais. São Paulo: Editora da Universidade de São Paulo, 2011.

MOIZÉS, Fábio Alexandre. Painéis de bambu, uso e aplicações: uma experiência didática nos cursos de Design em Bauru, São Paulo. 2007. 113f. Dissertação (Mestrado em Design) - Faculdade de Arquitetura, Artes e Comunicação, Universidade Estadual Paulista Júlio de Mesquita Filho, Bauru, 2007.

MOURA, Luiz Fernando; BRITO, José Otávio. Efeito da termorretificação sobre as propriedades colorimétricas das madeiras de Eucalyptus grandis e Pinus caribaea var. hondurensis. Piracicaba: Scientia Forestalis, v.39, n.89, mar. 2011.

NETO, João Amato. Sustentabilidade \&produção: teoria e prática para uma gestão sustentável. São Paulo: Atlas, 2011.

PEREIRA, Marco Antônio dos Reis; BERALDO, Antonio Ludovico. Bambu de corpo e alma. Bauru: Editora Canal 6, 2008.

RAMOS, Bruno Perazzelli Faria. Metodologia de curvatura de bambu laminado colado (BLaC) para a fabricação de mobiliário - diretrizes para o design. 2014. $115 f$. 
Dissertação (Mestrado em Design) - Faculdade de Arquitetura, Artes e Comunicação, Universidade Estadual Paulista Júlio de Mesquita Filho, Bauru, 2014.

ROSA, Sergio Eduardo Silveira da et al. $\mathbf{O}$ setor de móveis na atualidade: uma análise preliminar. Rio de Janeiro: BNDES Setorial, 2007.

WWF Brasil. 0 planeta precisa de 1,5 ano para regenerar os recursos renováveis que consumimos em um ano. Disponível na internet por http em:

$<$ http://www.wwf.org.br/natureza_brasileira/especiais/pegada_ecologica/pegada_eco logica_global/>. Acesso em 09 jun. 2016. 